\title{
Os elementos constituintes do método de análise das escolas Clássica, Neoclássica e Novo- Clássica
}

\author{
Fernanda Calasans C. L. Pessoti ${ }^{1}$ \\ Gustavo Casseb Pessoti ${ }^{2}$
}

\begin{abstract}
Resumo: O presente trabalho aborda o método de investigação da teoria econômica clássica e das teorias que nominalmente a seguiram, a saber: neoclássica e novo-clássica. O objetivo do artigo é explicitar quais são os elementos analíticos empregados por essas escolas, apontando as convergências e adaptações ao longo do desenvolvimento da teoria econômica. O individualismo metodológico do pensamento clássico é adotado pelos neoclássicos e se transforma em aspecto central para a construção da chamada ciência econômica. Segunda a literatura, no período contemporâneo, a escola nova-clássica reforça o caráter racional e maximizador do indivíduo clássico e neoclássico, estendendo os fundamentos da análise microeconômica para o ambiente macroeconômico. No entanto, tais elementos constitutivos serviram muito mais para enfraquecer o poder de explicação dessas teorias sobre os diversos fenômenos econômicos do que para fortalecê-lo.
\end{abstract}

Palavras-chave: Economia. Método. Fundamentos.

Abstract: This paper discusses the research method of classical economic theory and theories that nominally followed, namely: neoclassical and new classical. The objective of this article is to explain what are the analytical elements employed by these schools, pointing out the similarities and adaptations throughout the development of economic theory. The methodological individualism of classical thought is assumed by neoclassic and becomes central to the construction of the so-called economic science. In the contemporary period, the new classical school reinforces the rational and maximizing character the classical and neoclassical individual, extending the fundamentals of microeconomic analysis to the macroeconomic environment. However, the constituents served more to weaken the explanatory power of these theories on the various economic phenomena than to strengthen it.

Keywords: Economy. Method. Fundamentals.

\section{Introdução}

Os séculos XVI e XVII foram de transformações importantes no que se refere ao desenvolvimento e surgimento de ideias sobre os mais diversos campos do conhecimento. Após um período caracterizado por muitos historiadores como a "idade das trevas", numa alusão à ausência de liberdade intelectual que marcou a Idade Média, as ideias dos pensadores iluministas ganham espaço e

\footnotetext{
${ }^{1}$ Bacharel em Economia pela Universidade Estadual do Sudoeste da Bahia (UESB). Mestre em Economia (PPGE/UFU). Doutoranda em Economia (PPGE/UFBA). Professora assistente do Departamento de Ciências Sociais Aplicadas (UESB), área de Economia.Email: fecalasans@gmail.com.

2 Bacharel em Ciências Econômicas pela Universidade Federal da Bahia (UFBA). Mestre em Desenvolvimento Regional (PPDRU-UNIFACS). Diretor de Indicadores e Estatísticas da Superintendência de Estudos Econômicos e Sociais da Bahia (SEI). Professor Adjunto da Universidade de Salvador (UNIFACS). Email: cassebpessoti@gmail.com.
}

Página 230 Caderno de Ciências Sociais Aplicadas, Vitória da Conquista/BA, vol. 14, n 24, ano 14, p. 230-246, jul/dez 2017. 
influenciam aquela que seria a primeira a sistematizar o debate sobre "as relações entre os homens, na reprodução da vida material" (COUTINHO, 1990, p. 9): a chamada Economia Política.

A Economia Política nasce, assim, influenciada pelo pensamento iluminista, fundamentado na racionalidade e, em curto espaço de tempo, ganha evidência, impulsionada pelo próprio desenvolvimento das relações econômicas de produção que começam a se intensificar a partir do século XVIII nos principais países europeus da época, com destaque para a Inglaterra. De acordo com Coutinho (1990, p. 9):

Filósofos e naturalistas, muitos dos quais formados na tradição filosófica e científica do iluminismo, integram a nova reflexão do racionalismo. Transformam os temas da vida mercantil (e as relações de produção por eles expressadas) em objeto de conhecimento sistemático, submetidos à disciplina intelectual do racionalismo. Dão aos assuntos econômicos o estatuto de campo de investigação científica. Em suma, fundam uma nova ciência; o que, se é pouco perceptível em meados do século XVII, ter-se-á tornado evidente entre a última década deste, e a primeira do século posterior.

Apesar de o iluminismo ser apontado frequentemente como uma importante influência às ideias fundantes da Economia Política, ele não pode ser considerado como a única. Coutinho (1990) destaca a existência de três perspectivas de análise acerca das raízes da Economia Política. A primeira delas seria a filosófica, já destacada, que tem no iluminismo e no primado da razão as suas bases. Sob a ideia de racionalidade extraída do jusnaturalismo, "o "homem econômico", assim como a natureza humana, serão um dado da razão" (COUTINHO, 1990, p. 17), ou seja, a natureza humana é vista como uma construção racional, cujo comportamento é previsível e regular.

A segunda das perspectivas apresentadas por Coutinho (1990) se refere às controvérsias sobre temas econômicos, oriundas do crescimento das relações econômicas a partir do próprio desenvolvimento do sistema capitalista. A última, mas nem por isso menos importante, perspectiva de análise seria a influência da ideologia liberal, que "[...] representa a face econômica do iluminismo, ao considerar a existência de leis econômicas naturais, cuja existência o governo deveria esforçar-se por preservar" (COUTINHO, 1990, p. 26).

De fato, ao se analisar as primeiras construções teóricas dos economistas clássicos, é fácil identificar a presença de tais aspectos: racionalidade, relações econômicas de produção e liberalismo. Esses aspectos são determinantes para se entender o método de investigação adotado pela Economia Política, pois eles estão diretamente relacionados a forma de apreensão e observação da realidade que caracteriza a Economia Política Clássica (EPC).

Página 231 Caderno de Ciências Sociais Aplicadas, Vitória da Conquista/BA, vol. 14, n 24, ano 14, p. 230-246, jul/dez 2017. 
As escolas de pensamento econômico que surgiram tendo como base os argumentos clássicos foram, aos poucos, se distanciando da parte "política" da economia e empenharam-se em transformar a economia política em ciência econômica. Este papel foi cumprido inicialmente pela Escola Neoclássica e, mais recentemente, pela Escola Novo-clássica. O objetivo deste trabalho é apresentar os principais elementos constitutivos do método de investigação destas escolas - Clássica, Neoclássica e Novoclássica - e os aspectos que foram adicionados e/ou adaptados conforme a evolução do pensamento econômico. Deste modo, o problema de pesquisa norteador do trabalho é verificar a existência de similaridades e discrepâncias entre essas três escolas de pensamento.

O trabalho está dividido em cinco seções, incluindo esta introdução. A seção seguinte apresenta as principais características do método de análise utilizado pelos economistas clássicos, em especial Adam Smith, e as críticas de Marx ao individualismo metodológico, base do argumento clássico. A terceira seção trata das modificações feitas pela teoria neoclássica ao método clássico, que serviram de base para a construção da ciência econômica. Na sequência, são abordados os principais argumentos expostos pela teoria Novo-clássica, principalmente sobre o funcionamento dos mercados. A última seção traz as considerações finais do trabalho.

Convém ressaltar que não é objetivo deste artigo esgotar todas as congruências e incongruências existentes entre essas três escolas. Todas elas possuem contribuições de uma diversidade de autores que não poderiam ser abordadas em um trabalho como o aqui apresentado. Assim, espera-se apenas que os elementos destacados incentivem as discussões sobre a importância do método nas investigações e análises econômicas.

\section{O individualismo metodológico da Economia Clássica}

A análise da Economia Política Clássica (EPC) sobre o sistema econômico está centrada na noção de progresso e no individualismo metodológico: o indivíduo é visto como um ser naturalmente racional que age visando o auto interesse e, ao agir assim, garante o bem-estar coletivo. Ou seja, admitese que o indivíduo possui características naturais intrínsecas que o levam a agir de forma racional, características estas que não são determinadas pelo contexto histórico em que ele está inserido.

Entre essas características, está a propensão à troca, que motiva o estabelecimento de relações comerciais entre os indivíduos. Esta propensão natural à troca se constitui na base de formação do sistema capitalista, que teve suas relações de produção naturalmente intensificadas com o passar do

Página 232 Caderno de Ciências Sociais Aplicadas, Vitória da Conquista/BA, vol. 14, n 24, ano 14, p. 230-246, jul/dez 2017. 
tempo. Fatores que inibam a liberdade do indivíduo em atuar no sistema econômico são compreendidos como violação ao direito natural.

Este instrumental analítico está presente na obra de Adam Smith, considerado o primeiro autor da Escola Clássica e da Economia Política. Suas ideias e argumentos serviram de base para o desenvolvimento de toda a Economia Política, seja para as escolas de pensamento que se fundamentaram no seu método de investigação, seja para as correntes de investigação que realizam a crítica da sua análise sobre o funcionamento do sistema econômico.

No seu livro "[Origem e Causa de] A Riqueza das Nações", é nítida a influência das ideias liberais e iluministas. Sua análise se baseia em reconhecer o indivíduo como dotado de características naturais que determinam o seu comportamento e a sua atuação na sociedade, impulsionada pelo desejo de progredir. A liberdade é o que permite a reconciliação entre o desejo pessoal e o bem comum, de modo que o progresso pode gerar efeitos positivos (COUTINHO, 1990). Assim, o liberalismo “[...] reconcilia progresso material e ação individual; liberdade política e riqueza do Estado; ética dos fundamentos e sistema de propriedade privada" (COUTINHO, 1990, p. 105). Este último elemento é o que caracteriza o objeto de estudo da EPC: a riqueza privada.

Para Smith, a riqueza é entendida como produção de mercadorias. Dado que o homem é um ser cujas necessidades são crescentes (haja vista o desejo de progredir), tornam-se crescentes também as demandas, o que resulta em uma expansão da necessidade de trabalho. O atendimento dessas demandas crescentes é garantido pela especialização do trabalho, ou seja, pela divisão do trabalho, “[...] noção que articula o sistema teórico smitheano, remetendo, por um lado, ao aumento da produtividade e às condições materiais da produção; por outro, à lógica subjetiva das necessidades, ao interesse individual e à disposição do ser humano à troca" (COUTINHO, 1990, p. 111).

A sociedade analisada por Smith é uma sociedade de trocas de mercadorias, sendo o trabalho considerado a medida do valor de troca dessas mercadorias. Mais ainda, o trabalho é a fonte primaz de valor. E ao se reportar ao trabalho, Smith se refere ao "[...] trabalho puro e simples, isto é, nem o trabalho industrial, nem o trabalho comercial, nem o trabalho agrícola, mas todas essas formas de trabalho" (MARX, 1982, p. 16). A teoria do valor de Smith se estabelece como a teoria do valor trabalho, sendo que a acumulação de riqueza requer a expansão da produtividade do trabalho, garantida pela divisão do trabalho.

$\mathrm{Na}$ verdade, a sociedade analisada por Smith é apenas a soma de vários indivíduos, um todo constituído por suas partes e a partir das quais é explicado. A despeito de reconhecer a existência de

Página 233 Caderno de Ciências Sociais Aplicadas, Vitória da Conquista/BA, vol. 14, n 24, ano 14, p. 230-246, jul/dez 2017. 
classes sociais (capitalistas, trabalhadores e proprietários de terras) como agentes econômicos (COUTINHO, 2000, p. 117), o coletivismo é visto como a "agregação do individualismo"; o interesse coletivo é entendido como resultado do interesse individual. Essa visão da sociedade é incorporada à análise de outros pensadores da EPC.

A contribuição de Smith ao pensamento econômico é indiscutível. A sua percepção do processo de geração de riqueza em um sistema econômico dominado pelas relações de troca e a sua originalidade em estabelecer uma análise geral desse sistema permitiram a construção de um campo de reflexão das relações de produção nas sociedades modernas. A metodologia utilizada por Smith no desenvolvimento dessa análise, fundamentada no jusnaturalismo, no individualismo e no liberalismo, influenciou todo o arcabouço metodológico da EPC e, em níveis diferenciados, importantes escolas de pensamento econômico, como a corrente neoclássica.

Entretanto, apesar de sua originalidade e destacada contribuição, as ideias smitheanas foram criticadas por alguns autores do pensamento econômico que as sucederam. A intensificação das relações de produção demonstrou que as proposições de Smith não se aplicavam a níveis crescentes de desenvolvimento do sistema capitalista. Os autores clássicos que o seguiram tentaram adaptar e ajustar os seus argumentos, mas sem, de certo modo, abrir mão do método por ele empregado, que se reforça como o ponto comum da EPC. Mesmo que se admita a existência de diferenças na interpretação da forma de organização do sistema econômico, a análise continua centrada no indivíduo. Assim, uma característica da EPC é o individualismo metodológico.

Esse método de investigação utilizado pela EPC é criticado por Marx, que também reconhece pontos positivos na análise realizada pelos clássicos, tal como a "[...] a percepção do caráter de classe da sociedade em que viviam" (PAULANI, 2000, p. 102). Suas críticas partem de seu entendimento de que a EPC cometeu o equívoco de se deter apenas na aparência das relações sociais, sem procurar entender as particularidades intrínsecas às relações de produção no sistema capitalista. Essa visão superficial da sociedade é resultado do método de investigação utilizado pelos clássicos, que, segundo Marx, é errôneo.

O método de investigação utilizado por Marx e defendido por ele, é a lógica dialética, que tem por base filosófica o materialismo histórico, em contraposição ao método da lógica formal adotado pelos clássicos [(GERMER, 2000); (MARX; ENGELS, 1982). O processo de formação do conhecimento da Economia é realizado em duas etapas: 1) inicia-se no concreto real (realidade material e sua representação mental) e direciona-se para o abstrato, resultando em determinações simples de 
relações sociais; 2) faz-se o caminho de retorno do abstrato para o concreto, mas não mais o concreto real, e sim o concreto pensado (GERMER, 2000).

O concreto pensado é o resultado do conhecimento, constituído por partes da realidade, que são partes do concreto real elaboradas pelo pensamento a partir das abstrações simples (primeira fase do processo de formação do conhecimento). Assim, não é possível compreender a realidade material sem percorrer a estrada que leva ao conhecimento concreto pensado. Nas palavras de Marx (1982, p.14),

O concreto é concreto porque é a síntese de muitas determinações, isto é, unidade do diverso. Por isso, o concreto aparece no pensamento como o processo da síntese, como resultado, e não como ponto de partida, ainda que seja o ponto de partida efetivo e, portanto, o ponto de partida também da intuição e da representação.

O erro metodológico dos economistas clássicos se inicia por não compreenderem este processo de construção do conhecimento. De acordo com Paulani (2000, p. 101), para Marx:

[...] os pensadores clássicos são iludidos pelo fato de que o concreto aparece para o pensamento como resultado, quando, em verdade, ele é o ponto de partida efetivo [...]. É por não esquecerem de fazer a viagem de volta - do abstrato à realidade concreta -, afirma Marx, que eles não perceberam a especificidade e o caráter historicamente condicionado de suas "descobertas" e das categorias que essa mesma realidade lhes permitiu forjar.

Em outras palavras, a análise da EPC está circunscrita a uma análise superficial da realidade capitalista, que a impede de ver as relações sociais entre os indivíduos ou entre as classes sociais como condicionadas pela história. Para os clássicos, a produção é "regida por leis naturais, eternas, independentes da História” (MARX, 1982, p. 5). Na visão de Marx, a produção é afetada por condições históricas, de maneira que uma determinada forma de produção determina o consumo, a distribuição e a troca e as relações desses fatores entre si (MARX, 1982, p.13). Uma vez que estão limitados à aparência das relações de produção no sistema capitalista, os autores clássicos não conseguem reconhecer o comportamento humano como resultado não apenas de elementos da natureza humana, mas também de elementos sociais e históricos que condicionam e determinam o comportamento dos indivíduos.

Tal fato torna o indivíduo estabelecido por Smith e, também, por Ricardo um ser que não condiz com aquele que faz parte da realidade capitalista. Nas palavras de Marx (1982, p. 3), este indivíduo é visto, in verbis

Página 235 Caderno de Ciências Sociais Aplicadas, Vitória da Conquista/BA, vol. 14, n² 24, ano 14, p. 230-246, jul/dez 2017. 
[...] não como um resultado histórico, mas como ponto de partida da História, porque o consideram como um indivíduo conforme à natureza [...] que não se originou historicamente, mas foi posto como tal pela natureza. [...] Só no século XVIII, na "sociedade burguesa", as diversas formas do conjunto social passaram a apresentar-se ao indivíduo como simples meio de realizar seus fins privados, como necessidade exterior. Todavia, a época que produz esse ponto de vista, o do indivíduo isolado, é precisamente aquela na qual as relações sociais [...] alcançaram o mais alto grau de desenvolvimento. O homem é [...] não só animal social, mas animal que só pode isolar-se em sociedade.

Essa visão "naturalizada" do indivíduo não permite a EPC identificar o verdadeiro objeto da Economia Política, a saber, as relações sociais entre indivíduos e entre classes [GERMER (2000); OSORIO (2004)]. A sociedade capitalista não é apenas uma sociedade de trocas, como supõem os clássicos, mas uma sociedade condicionada pelas relações sociais, hierarquizadas, em que categorias econômicas não possuem o mesmo poder de atuação e de influência na organização do sistema (OSORIO, 2004). Portanto, essa sociedade não pode ser vista como a soma de indivíduos que atuam buscando o auto interesse. Ou seja, o todo não pode ser visto como a simples soma das partes, pois existem relações entre as partes (categorias) que intensificam a complexidade do todo.

Deste modo, a totalidade é vista por Marx de maneira distinta daquela vista pelos clássicos. Parte-se do fato de que ela, a totalidade, é contraditória, uma vez que forças e interesses distintos se confrontam internamente, ora se configurando em unidade, ora em luta de opostos (OSORIO, 2004).

Sendo a totalidade não apenas a aglomeração de indivíduos, ou seja, a soma das partes, a produção social dessa sociedade não pode ser vista como um conjunto de produtos individuais. A produção dessa sociedade também é condicionada social e historicamente, assim como são os indivíduos que a compõem. Portanto, não se trata apenas de uma sociedade produtora de mercadorias, como definem os clássicos. É uma sociedade de relações de produção, determinadas social e historicamente. A mercadoria é apenas o "produto aparente" dessa sociedade. Por trás dela, há um complexo sistema de inter-relação de categorias econômicas, que define e é definido pela estrutura de classes. Assim, este produto apresenta um individualismo aparente, pois é fruto de uma produção social, baseada no trabalho combinado socialmente [(PAULANI, 2000); (CORAZZA, 1996)].

\section{A cientificidade da teoria Neoclássica}

A teoria econômica neoclássica exerce grande influência na forma como é comumente apresentada a Economia. Seja nos meios de comunicação, seja nas escolas de formação dos futuros 
economistas, ou ainda nas políticas econômicas, há uma predominância, pelo menos aparente, da análise dos fenômenos econômicos desenvolvida por esta corrente teórica, razão pela qual ela é também chamada de mainstream do pensamento econômico. Em situações mais extremas, mas nem por isso menos frequentes, o neoclassicismo se confunde com a própria definição do que seria a Economia, do que é o seu objeto e de como se estrutura a sua análise investigativa.

Obviamente, trata-se de uma interpretação equivocada e deturpada da Economia como ramo do conhecimento intelectual e científico. Talvez o que mais contribua para este predomínio da teoria neoclássica seja a tarefa assumida por esta teoria desde a fase inicial de sua construção de elevar a Economia à categoria de ciência, entendida no sentido de ciência positiva.

A visão de que o comportamento dos indivíduos é regido por leis naturais e de que a sociedade, que representa a soma dos indivíduos, se organiza com base nesse mesmo tipo de lei - tal qual como apontado pela escola clássica - induz os neoclássicos a afirmarem que o objetivo da Economia enquanto ciência é encontrar as leis que determinam esse comportamento.

O pressuposto básico é, portanto, de que existem leis que regem as relações econômicas e o comportamento dos indivíduos [(PRADO,1994); (PAULANI, 2005); (GUIMARÃES AUGUSTO, 2010)]. Ainda que se baseando em elementos constitutivos da Economia Política Clássica, o argumento neoclássico se configura em um aprofundamento do individualismo metodológico empregado pelos clássicos, principalmente por centrar a sua análise explicitamente na categoria de agente econômico e abandonar qualquer referência às classes sociais.

O individualismo adotado por essa escola é associado à ideia de que os indivíduos, na sociedade moderna, são livres e agem de maneira autônoma buscando o auto interesse. Mais ainda, esses indivíduos buscam a maximização de sua utilidade. A utilidade é a novidade do individualismo metodológico dos neoclássicos. De acordo com a corrente filosófica utilitarista, as pessoas agem de maneira a ampliar a sua felicidade, de modo que as ações são consideradas boas se esse objetivo é alcançado e más se o contrário ocorre. As decisões passam a ser entre felicidade (prazer ou ausência de dor) e dor (ausência de prazer) (PAULANI, 2005).

E como tomar a melhor decisão? Em outras palavras, como maximizar a utilidade? A resposta é simples: agindo racionalmente. Admitir que o indivíduo maximiza utilidade requer que se pressuponha que esse indivíduo aja de maneira racional; que ele tenha capacidade de realizar o cálculo de utilidade que permita a maximização. A racionalidade é uma característica natural do indivíduo, responsável pela otimização da ação. As pessoas sempre decidem por um ganho maior em detrimento de um ganho

Página 237 Caderno de Ciências Sociais Aplicadas, Vitória da Conquista/BA, vol. 14, n 24, ano 14, p. 230-246, jul/dez 2017. 
menor. Há uma lei psicológica, intrínseca ao ser humano, de maximização de resultado, comandada pelo pleno conhecimento, ou seja, pela racionalidade.

$\mathrm{Na}$ escola neoclássica, portanto, a utilidade é a motivação para o agir e a racionalidade o modo segundo o qual os indivíduos agem (GUIMARÃES AUGUSTO, 2010). A dificuldade na mensuração da utilidade levou alguns autores neoclássicos a associarem este conceito ao de preferências, que se apresenta, segundo Guimarães Augusto (2010), em duas versões, a saber:

\begin{abstract}
Nas preferências reveladas, os motivos - as preferências - são deduzidas a partir do comportamento observado dos agentes. [...] a escolha do agente revela a suas preferências. [...] As preferências intrínsecas, ao contrário das reveladas, tomam como ponto de partidas as preferências dos agentes, sendo a escolha destes deduzidas a partir das preferências (GUIMARÃES AUGUSTO, 2010, p. 228).
\end{abstract}

Nota-se que a tentativa de reduzir a subjetividade do conceito de utilidade não resulta em um conceito objetivo. A mensuração das preferências também não é algo possível. Por isso, a saída encontrada é estabelecer uma escala de preferências, associada sempre à ideia de que o agente prefere mais a menos. O processo de maximização, como já mencionado anteriormente, está condicionado à racionalidade do agente. $\mathrm{Na}$ visão neoclássica, essa racionalidade é admitida por alguns autores como perfeita (fase inicial da teoria) e, por outros, como limitada. No entanto, as características permanecem nas duas definições de racionalidade adotadas [(PRADO, 1994); (PRADO, 1996); (GUIMARÃES AUGUSTO, 2010)]. Ao tratar da racionalidade neoclássica, Prado (1996, p.14) afirma que

[...] é iluminista, já que é encarada como faculdade do indivíduo autônomo. [...] ela concerne ao ato de conhecer para articular meios e fins, sendo chamada por isso de cognitiva e instrumental. [...] em sua condição de instrumental, opõe-se fortemente à ideia de racionalidade normativa. [...] enquanto um atributo individual, pressupõe um agente econômico centrado em si mesmo, que conhece os fenômenos do mundo de modo perfeito e objetivista.

A definição da racionalidade neoclássica como cognitiva e instrumental merece uma atenção especial por estar diretamente relacionada ao modo de agir do indivíduo. Este, é capaz de escolher o melhor meio para atingir o fim que ele objetiva, pois tem conhecimento dos meios existentes. Os objetivos são coerentes aos meios e os meios coerentes aos objetivos. Essa coerência não está relacionada diretamente com nenhuma definição de justiça, ética ou juízo de valor, isto é, "nunca se

Página 238 Caderno de Ciências Sociais Aplicadas, Vitória da Conquista/BA, vol. 14, nº 24, ano 14, p. 230-246, jul/dez 2017. 
envolve com a questão de saber se estes [objetivos] são corretos, justos ou bons” (PRADO, 1996, p. 22).

Os objetivos são definidos pelos desejos, que são tomados como dados primários da ação (PRADO, 1996). Diante da possibilidade de ter vários objetivos, supõe-se que o indivíduo, como base na sua racionalidade, decida pelo objetivo que resulte em maior satisfação - ou maior utilidade - dadas suas preferências. Esta decisão pode não resultar numa situação ótima, mas resulta na melhor situação possível dado os meios existentes.

Assim, no processo de escolha, o agente econômico racional emprega não só os meios adequados para atingir os fins desejados, mas também os meios mais eficientes, nos termos esposados por Guimarães Augusto (2010, p. 231), verbis: “uma ação é racional se utiliza os meios adequados para os fins, não realiza sacrifício desnecessário de meio e se o agente escolhe fins congruentes".

Essa hipótese da ação racional que baliza o comportamento maximizador do agente é o que permite que se estabeleça um padrão de comportamento e, consequentemente, que haja previsibilidade. Uma vez que a ação é fruto de um "raciocínio demonstrativo, claro, seguro e exato" (PRADO, 1996, p. 26), é perfeitamente possível que ela seja previsível, calculada, transformada em um conjunto de relações matemáticas; em outras palavras, formalizada.

Já que a sociedade é vista como o conjunto das ações individuais, o seu funcionamento e a sua organização também estão condicionadas pela racionalidade e pela maximização. Na verdade, a sociedade é substituída pelo mercado, espaço onde os agentes econômicos atuam. Isso significa que a formalização e a previsibilidade também podem ser realizadas em termos da sociedade. E, com isso, os neoclássicos alcançam o seu objetivo de transformar a Economia Política numa ciência: a ciência econômica.

Vale acrescentar que qualquer intervenção no espaço onde os indivíduos agem, ou seja, no mercado, é considerada como um distúrbio dessa ordem racional naturalmente estabelecida. Por isso, a defesa da liberdade de ação dos agentes é algo tão ressaltado pelos neoclássicos. Os agentes são livres para atuar no mercado, ofertando e demandando produtos, serviços e fatores de produção. Essa atuação é determinada pelas decisões que os agentes tomam baseadas na racionalidade e na maximização da satisfação (utilidade). Sendo o mercado o todo que representa a soma dos indivíduos, existem também leis naturais que determinam o seu funcionamento, assim como acontece com o comportamento dos agentes. Tais leis não devem ser alteradas por intervenções, principalmente aquelas advindas da ação governamental.

Página 239 Caderno de Ciências Sociais Aplicadas, Vitória da Conquista/BA, vol. 14, n 24, ano 14, p. 230-246, jul/dez 2017. 
Individualismo, liberalismo, utilitarismo e racionalidade são elementos constitutivos do arcabouço metodológico neoclássico sobre os quais se fundamenta toda a construção teórica dessa escola de pensamento. É difícil estabelecer qual desses elementos possui maior influência no pensamento neoclássico, haja vista a inter-relação existente entre eles.

\section{A otimização da Escola Novo-Clássica}

A Escola Novo-Clássica surge na década de 1970 como uma proposta de interpretação do fenômeno de estagflação que caracterizou algumas economias capitalistas durante essa década. Mais do que isso, essa escola de pensamento se propõe a analisar o ciclo econômico de negócios com base na abordagem de equilíbrio geral [(FERRARI FILHO, 1996); (VERCELLI, 1991); (LIBÂNIO, 1997)]. A discussão macroeconômica da época era dominada pelo debate entre os adeptos das ideias keynesianas e os seguidores das ideias monetaristas de Friedman. Na visão novo-clássica, ambas ideias estariam equivocadas e não promoveriam um diagnóstico adequado da situação vivenciada. Assim, os economistas novos-clássicos defenderam uma contra-revolução antikeynesiana, conforme apontado por Vercelli (1991, p. 128):

Lucas's research programme is meant to implement in practice a sort of anti-Keynesian counterrevolution. His main aim is to re-establish classical theory in a more advanced and satisfactory version which can take account of macroeconomic phenomena and provide firm criteria for choosing between alternative economic policies.

Lucas é considerado um dos mais expressivos autores novo-clássicos e seu pensamento está fundamentado na afirmação de que a estrutura de análise da Teoria Clássica ainda seria o melhor instrumental de investigação dos fenômenos econômicos. Por isso, Lucas e os demais economistas novos-clássicos concentram seus esforços em interpretar os fenômenos macroeconômicos com base nos microfundamentos da teoria econômica convencional. A crítica feita por esses economistas não se limita ao pensamento keynesiano original, mas também às escolas de pensamento que, de alguma forma, incorporaram elementos presentes nas formulações propostas por Keynes, tais como os autores da Síntese Neoclássica (VERCELLI, 1991).

A influência do pensamento clássico e neoclássico na teoria novo-clássica é perceptível já na definição de sistema econômico e do comportamento dos agentes. Para essa corrente teórica, a economia é essencialmente formada por indivíduos atômicos que otimizam uma função-utilidade com

Página 240 Caderno de Ciências Sociais Aplicadas, Vitória da Conquista/BA, vol. 14, nº 24, ano 14, p. 230-246, jul/dez 2017. 
base em suas expectativas racionais. De partida, é possível sintetizar três elementos que fundamentam essa definição e que caracterizam, de alguma forma, o pensamento econômico ortodoxo: atomização, otimização e racionalidade.

Os pressupostos de que a economia (o todo) é uma simples soma da ação individual dos agentes (as partes) de que a ação dos agentes é maximizadora, de utilidade, permite que a análise do comportamento dos agentes seja estendida à análise do comportamento do sistema econômico. Assim, não haveria equívoco em empregar os microfundamentos na análise macroeconômica.

O terceiro elemento que fundamenta o pensamento novo-clássico merece maior atenção por se constituir em um aspecto até certo ponto inovador. A hipótese das expectativas racionais (HER) advoga que os agentes conseguem realizar previsões corretas sobre o futuro, uma vez que as informações necessárias para a realização desse cálculo estão disponíveis. Diferentemente da visão monetarista de expectativas adaptativas, “[...] o valor esperado de uma variável não é, necessariamente, uma função estável de seus valores passados" (FERRARI FILHO, 1996), mas sim do seu valor esperado condicionado às informações observadas.

A HER tem como premissa básica o conhecimento do futuro, ou seja, a capacidade de prever os acontecimentos futuros. A incerteza pode ser calculada e é transformada em "risco", o que difere em essência do pensamento keynesiano. O cálculo da incerteza é possível mediante o conhecimento da distribuição de probabilidade. A racionalidade está, portanto, associada à capacidade de realizar o cálculo probabilístico, reduzindo a incerteza. Se algo ocorre diferente do previsto é em função de algum efeito aleatório, exógeno. Weeks (2010, p. 133) sintetiza a HER da seguinte maneira:

1) if economic and social relations are deterministic; 2) if all aspects of these deterministic relations are known by economic agents; 3) if economic agents form their predictions of the future on this complete knowledge; then 4) the predictions (expectations) formed in this manner will be correct on average and any divergence between anticipated and actual outcomes will be the result of random influences.

À luz das lições de Weeks (2010), existem dois tipos de influência na definição do resultado futuro, exigindo a realização de um procedimento de identificação: as influências sistemáticas, que se constituem no conhecimento; e as influências desconhecidas, ou seja, os eventos aleatórios. Deste modo, há a necessidade de se distinguir entre as fontes dos desvios em torno da média. Se esses desvios são sistemáticos, o modelo de previsão deve ser alterado para corrigi-lo; se os desvios são resultados de desvios aleatórios em torno da média, não há necessidade de modificar o modelo, pois os erros seriam

Página 241 Caderno de Ciências Sociais Aplicadas, Vitória da Conquista/BA, vol. 14, n 24, ano 14, p. 230-246, jul/dez 2017. 
incorporados no termo estocástico. A HER admite que mesmo sob as melhores condições, alguns indivíduos podem não agir conforme o previsto. No entanto, eles podem se aproximar do modelo correto pelo processo de tentativa e erro que, nas palavras de Week (2010, p. 135), "[...] is the last line of defense of the REH [HER]".

Outra hipótese fundamental do arcabouço teórico da escola novo-clássica é de que a economia está sempre em equilíbrio, sendo que os preços se ajustam instantaneamente [(FERRARI FILHO, 1996); (VERCELLI, 1991); (LIBÂNIO, 1997); (WEEKS, 2010)]. Esse ajuste automático dos preços está baseado nas premissas de racionalidade e otimização do comportamento dos agentes. Na medida em que os agentes agem de maneira racional - haja vista que eles detêm as informações necessárias para realização de tal ação - e buscam a otimização de seus resultados, as modificações nos preços são prontamente percebidas pelos indivíduos.

O auto equilíbrio do sistema econômico está fundamentado no equilíbrio geral walrasiano. Uma vez que o mercado de trabalho está em equilíbrio, todos os demais mercados também estão. A análise se inicia por este mercado porque os novo-clássicos centram suas atenções na oferta agregada. Segundo Weeks (2010), o equilíbrio walrasiano requer a hipótese de previsão perfeita e a escola novo-clássica adiciona a esta a hipótese de expectativas racionais. Deste modo, a "[...] assumption of perfect foresight is required to ensure the Market clearing that establishes full employment each market period, and the REH [HER] does no more than provide a spurious link between one market period and the next" (WEEKS, 2010, p. 141).

Para determinar o equilíbrio no mercado de trabalho, o pensamento novo-clássico pressupõe que os trabalhadores, ao negociarem seus salários, possuem informação completa, que também está disponível para os empresários (detentores de capital). Ou seja, que ambas as partes envolvidas na negociação do preço do trabalho conhecem o mesmo modelo completo formal de funcionamento da economia (WEEKS, 2010). Além disso, tanto os trabalhadores como os empresários tomam decisões que refletem o seu comportamento otimizador, sendo que a oferta de trabalho pelos trabalhadores é realizada com base nos preços relativos e as mudanças no nível de emprego são uma resposta dos trabalhadores a variações no salário real. O mesmo acontece com as decisões de produção dos empresários.

Uma vez que os agentes detêm as informações disponíveis e são racionais, os trabalhadores interpretam o aumento nos salários nominais como um aumento transitório nos salários reais e por isso, estão dispostos a aumentar a oferta de trabalho até que o efeito transitório nos preços relativos se esgote e os salários reais retornem ao seu nível normal. Na visão de Lucas, apresentada por Vercelli

Página 242 Caderno de Ciências Sociais Aplicadas, Vitória da Conquista/BA, vol. 14, n 24, ano 14, p. 230-246, jul/dez 2017. 
(1991), isso seria a explicação para as oscilações no nível de emprego, que têm correlação com as oscilações nos preços e nos salários monetários. Ainda segundo este autor, "in this perspective there is no place for involuntary unemployment because the market for labour is always "cleared" and the workers are always on the labour suplly curve" (VERCELLI, 1991, p. 131).

Os salários nominais são negociados e fixados para cada período de tempo com base nas expectativas dos agentes. Essas expectativas racionais resultam em um salário real esperado que mantenha o desemprego a uma taxa natural. Esta taxa seria aquela que prevalece quando o mercado de trabalho está em equilíbrio, isto é, operando na situação ideal. Para a escola novo-clássica, a taxa natural de desemprego se refere àqueles indivíduos que optam por ficar desempregados (WEEKS, 2010). Desvios na taxa natural de desemprego não seriam benéficos para os ofertantes nem para os demandantes de trabalho.

É preciso retornar à hipótese de que os agentes agem de modo a otimizar seus resultados para entender que a situação de equilíbrio, na qual o mercado de trabalho opera com taxa de desemprego natural, é aceita pelos trabalhadores. $\mathrm{Na}$ verdade, esta situação seria o resultado ótimo de organização do mercado do trabalho e ir de encontro a ela seria abandonar a hipótese de racionalidade.

Uma vez que trabalhadores e empresários (trabalho e capital) conhecem o modelo correto de funcionamento da economia, ou seja, não existe assimetria de informações entre eles; agem de modo racional; e possuem o mesmo objetivo de estabelecer o nível de salário real de equilíbrio, não há espaço para a existência de um conflito distributivo (WEEKS, 2010). Assim, na teoria novo-clássica, "[...] completely ignored is the possibility that the wage bargain might involve a struggle over the distribution between wages and profits" (WEEKS, 2010, p. 140).

Por se tratar de uma teoria fundamentada no equilíbrio geral, o equilíbrio do mercado de trabalho está associado ao equilíbrio nos demais mercados, sendo o ponto de equilíbrio do sistema definido pela taxa natural do produto e pela taxa natural de desemprego. As flutuações econômicas seriam apenas desvios em torno dessas taxas. Estes desvios seriam rapidamente corrigidos pelo mecanismo de auto ajustamento do mercado, não sendo necessário nenhum tipo de intervenção exógena (leia-se governamental). No caso de existir alguma intervenção, ela deve ter regras claras e transparentes, disponíveis à todos os agentes.

As críticas direcionadas à escola novo-clássica destacam que as formulações teóricas dessa escola estão condicionadas a um forte grau de abstração da realidade. O argumento por trás do arcabouço teórico novo-clássico é de que o mundo real funciona como resultado de uma teoria correta,

Página 243 Caderno de Ciências Sociais Aplicadas, Vitória da Conquista/BA, vol. 14, n 24, ano 14, p. 230-246, jul/dez 2017. 
de tal maneira que "os fenômenos concretos se apresentariam como se obedecessem aos determinantes colocados pela teoria" (LIBÂNIO, 1997, p. 143, grifo do autor). Nesse sentido, o sistema econômico funciona seguindo uma lógica determinística e a ação dos agentes é apenas a de processar informações e não a de produzir eventos.

\section{Considerações finais}

Os elementos constitutivos - individualismo, racionalidade e liberalismo - do método de análise da Economia Política Clássica foram aprofundados pelas escolas de pensamento que se intitularam seguidoras da teoria econômica clássica. Na verdade, a escola Neoclássica e a escola Novo-clássica extraíram do pensamento clássico apenas os argumentos que atendiam aos interesses dessas escolas em elevar a economia política ao patamar de ciência positivista. Como aspecto comum e limitador da análise dessas três escolas está a ausência da historicidade.

O individualismo metodológico dos clássicos não permite o reconhecimento da "estrutura coletiva" determinada social e historicamente, o que torna a sua interpretação da sociedade capitalista limitada e dissociada do mundo real. O método empregado pelos clássicos não admite o ser humano como produto da história e a desconsidera como componente ontológico da realidade. A crítica de Marx tem o mérito de apontar esses equívocos de interpretação da realidade capitalista, sem, contudo, deixar de reconhecer a relevância intelectual e histórica da Economia Política Clássica.

A teoria neoclássica está fundamentada em pressupostos sobre o comportamento dos indivíduos, sendo esses pressupostos carregados de conteúdo psicológico. Na tentativa de transformar a Economia numa ciência, os neoclássicos estabeleceram uma série de restrições ao modo como os indivíduos agem e reduziram a estrutura social a um mercado onde são realizadas transações econômicas. Fatores históricos e temporais não são considerados na sua análise. Os indivíduos se comportam da mesma maneira em qualquer lugar, em qualquer tempo, pois o seu comportamento é fruto de características e capacidades naturais do ser humano.

Esse modelo de organização social, dizem os adeptos, não se compromete a ser uma representação da realidade, mas sim a sua simplificação. Isso significa que por trás da complexidade do instrumental matemático empregado existe um conjunto de proposições que simplificam a realidade. Tomando isso como verdadeiro, há de se perguntar por que é ainda tão usado como fundamento na construção de análises econômicas aplicadas, que por definição deveriam estudar a realidade. Mais uma

Página 244 Caderno de Ciências Sociais Aplicadas, Vitória da Conquista/BA, vol. 14, n 24, ano 14, p. 230-246, jul/dez 2017. 


\section{- CAdERNos de Ciénclas SOCIAIS APLICADAS}

vez a resposta é simples: os neoclássicos usam os meios mais adequados e eficientes conhecidos por essa escola para atingir o fim de se estabelecer como pensamento dominante entre os economistas. No entanto, a análise dos fundamentos do neoclassicismo demonstra que os neoclássicos são vítimas do próprio método que defendem: os meios que utilizam não são os mais adequados e os mais eficientes para entender as relações econômicas, de modo que o pressuposto da racionalidade, se fosse verdadeiro, não seria determinante da investigação por eles desenvolvida.

A tentativa dos economistas novos-clássicos de responder aos novos desafios empíricos apresentados pelo desenvolvimento da economia capitalista se apresenta, portanto, bastante limitada. Como uma teoria do ciclo econômico, a teoria nova-clássica se restringe a definir as flutuações como pontos de desequilíbrios temporários, sem procurar discutir as relações de produção que caracterizam o sistema capitalista, bem como a sua estrutura de organização social. Como alternativa à análise monetarista, a análise novo-clássica não consegue avançar para além da substituição da hipótese de expectativas adaptativas pela hipótese de expectativas racionais.

\section{Referências}

CORAZZA, G. O todo e as partes: uma introdução ao Método da Economia Política. Estudos Econômicos, São Paulo, v. 26, n. especial, p. 35-50, 1996.

COUTINHO, M. Lições de Economia Política. 1990. 226 fls. Tese (Livre Docência) - Instituto de Economia, Universidade Estadual de Campinas, Campinas, 1990.

. A Crítica da Economia Política: teoria e atualidade. Crítica Marxista, Campinas, n. 10, p. 122133, jan/jun, 2000.

FERRARI FILHO, Fernando. "Keynesianos", monetaristas, novos-clássicos e novos-keynesianos: uma leitura pós-keynesiana. Ensaios FEE, Porto Alegra, v. 17, n² 2, p. 78-101, 1996.

GERMER, C. M. Contribuição ao entendimento do método da economia política, segundo Marx. Curitiba, UFPR, 2000, mimeo.

GUIMARÃES AUGUSTO, A. Teoria da ação na Escola Neoclássica: uma resenha crítica. Pesquisa \& Debate, São Paulo, v. 21, n. 2 (38), p. 225-246, 2010.

LIBÂNIO, Gilberto A. Uma nota sobre Lucas e o vício Ricardiano. Revista de Economia Política, São Paulo, SP, v. 17, n. 4 (68), p. 140-146, 1997.

MARX, K. Para a Crítica da Economia Política. São Paulo: Abril Cultural, 1982. (Coleção Os Economistas).

Página 245 Caderno de Ciências Sociais Aplicadas, Vitória da Conquista/BA, vol. 14, n 24, ano 14, p. 230-246, jul/dez 2017. 
MARX, K.; ENGELS, F. Feuerbach: a oposição entre as concep̧ões materialista e idealista (Cap. 1 de A Ideologia Alemã). São Paulo: Ciências Humanas, 1982.

OSORIO, J. Crítica de la Economia Vulgar: reproducción del capital y dependencia. Colección América Latina y el Nuevo Ordem Mundial. México: Miguel Ángel Porrua, UAZ, 2004.

PAUlANI, L. A atualidade da crítica da Economia Política. Crítica Marxista, Campinas, n. 10, p. 111 121, jan/jun, 2000.

. Modernidade e Discurso Econômico. São Paulo: Boitempo, 2005.

PRADO, E. A constelação pós-walrasiana. Revista de Economia Política, São Paulo, v. 14, n. 4 (56), out/dez 1994. v. 26, 1996.

O caráter monológico da racionalidade neoclássica. Estudos Econômicos, São Paulo, n. especial,

VERCELLI, Alessandro. Methodological foundations of macroeconomics: Keynes and Lucas. Cambridge: Cambridge University Press.

WEEKS, John. False Paradigma: the irreconciable inconsistencies of neoclassical macroeconomics. School of Orient and African Studies, University of London, 2010. 